\title{
In-vitro Antimicrobial Activity of the Combined Effect of Kalanchoe Crenata and Vernonia Amygdalina on Salmonella Species
}

Emmanuel Effah-Yeboah ( $\nabla$ eeyeboah@uew.edu.gh )

University of Education https://orcid.org/0000-0003-2783-0613

Emmanuel Agyapong Asare

University of Education Winneba

Gadafi Iddrisu Balali

Kwame Nkrumah University of Science and Technology

\section{Research}

Keywords: antimicrobial, inhibition, sensitivity, Salmonella typhi, zones of inhibition and extracts

Posted Date: July 9th, 2020

DOI: https://doi.org/10.21203/rs.3.rs-31961/v1

License: (c) (i) This work is licensed under a Creative Commons Attribution 4.0 International License.

Read Full License

Version of Record: A version of this preprint was published at Annual Research \& Review in Biology on December 4th, 2021. See the published version at https://doi.org/10.9734/arrb/2021/v36i1130455. 


\section{Abstract}

Introduction

The major breakthrough in the treatment of pathogenic diseases was the unearthing of naturally occurring antipathogenic agents or antibiotics. There have been upsurges in antibiotic-resistant strains of clinically important pathogens, which made way to the emergence of new-fangled bacterial strains that are multi-resistant. The major aim of scientists is to develop new antibiotics or other therapeutic strategies at a pace greater than that at which bacteria are developing resistance. Development of resistance to first-line antimicrobial therapies made way to recommendations for combination therapies for the treatment of some infections and some of this form of chemotherapy seems to be very successful.

Objectives

This research was carried out the determine the effect of Kalanchoe crenata extract on salmonella Tyhi load. It was carried out to also assess the potency of the extract of Vernonia amygdalina on Salmonella typhi and also to ascertain the effect of the combined extract of Kalanchoe crenata and Vernonia amygdalina on salmonella typhi.

Method

In this research, Salmonella typhi was exposed to a crude extract of Kalanchoe crenata and Vernonia amygdalina and also the combination of the two extracts. Agar wells diffusion method was employed.

Results

The combined effect was not sensitive to the Salmonella strain. The Salmonella strain was resistant to $V$. amygdalina than to $K$. crenata. K. cranata had the strongest activity against $S$. typhi with its highest zone of growth inhibition of $20 \mathrm{~mm}$ and lowest zone of inhibition of $7 \mathrm{~mm}$ while $V$. amygdalina produced consistent zone of growth inhibition of 5-6 mm; The combined effect produced a zone inhibition diameter only at the $100 \mathrm{mg} / \mathrm{ml}$ with zone of inhibition value of $14 \mathrm{~mm}$. The subsequent lower concentrations did not show any activity against the microbes. At P-value $=0.05$ two-way ANOVA statistics exhibited significant difference amongst the effects produced by the different extracts, though there were no substantial differences in the effects produced by the various concentrations.

Conclusion

The salmonella strain was resistant to $V$. amygdalina than to $K$. crenata. At P-value $=0.05$ there was a substantial difference in the sensitivity of the bacteria to the different extracts.

\section{Introduction}


Microorganism normally referred to as microbes are a very important group of organisms in the environment. Various groups of these microbes exist; bacteria, virus and fungi are examples of major groups of microbes that exist [1]. These individual groups have some peculiar characteristics and properties and hence they tend to undergo different life activities to survive [2]. However, individuals in the same group usually have similar life activities but with few variations among members in the group [3]. When these microorganisms get into the human body and are able to overwhelm the immune system and also the normal resident microflora then they cause infectious diseases [4]. These bacteria responsible for many of the current infectious diseases are therefore referred to as the infectious agent (pathogens) [5].

\subsection{TYPHOID FEVER}

Typhoid fever is a bacterial infection that affects people globally and is caused by the bacterium Salmonella typhi. The disease can be transmitted through the bacterial contamination of water, milk, food, fruits and vegetables. Healthy carriers of the infection and even contaminated food handlers can transmit the disease to healthy individuals. The bacteria can also be carried from feces to food by flies [6]. The World Health Organization estimated an annual rate of about 12.6 million infections with about 600,000 possible deaths [7].

Poor food hygiene, poverty and inadequate supply of clean water has resulted in the increase in typhoid infections and acute gastroenteritis in African [8]. In recent years multidrug resistance to the typhoid infection has increased worldwide [9-11].

Due to the increase in resistance to the treatment of typhoid fever by antibiotics, herbal preparations are gaining popularity in both rural and urban areas in Africa for the treatment of the disease. These medicinal herbal preparations have less side effects compared to the chemical agents [12]. This work was carried out to investigate the combined effect of kalanchoe crenata and Vernonia amygdalina on salmonella typhi.

\subsection{VERNONIA AMYGDALINA}

$V$. amygdalina, which is commonly known as the bitter leaf, is one of the plants mostly exploited in West Africa [13]. Studies have proven many therapeutic properties of phytochemicals present in the plant [1315]. The antimicrobial activities of $V$. amygdalina on E. coli, Salmonella and Shigella $s p[16,17]$ have been experimented. The result revealed that the organisms were not as active except for Shigella $s p$ which showed considerable sensitivity [17]. It was further proven that the growth of gram positive bacterium Staphylococcus aureus and the gram negative bacterium $E$. coli have been strongly inhibited by the aqueous extracts of the leaves [18].

The entirety of the plant is pharmacologically useful [19]. Both the roots and leaves are utilized in phytomedicine for the treatment of kidney diseases, fever, stomach discomfort and hiccups, among others [20]. Bukar et al., (2013) affirmed that the sensitivity of $V$. amygdalina was more towards gram 
positive bacteria compared to the of gram-negative bacteria; However, other researchers revealed that the activity of $V$. amygdalina on gram-negative bacteria was comparable to its effect towards the grampositive species $[18,21]$. For example, methanol extract of $V$. amygdalina affected not only the growth of gram-positive bacteria such as $B$. subtilis, $B$. cereus, M. kristinae, B. pumilus, $S$. aureus and E. cloacae but exhibited potency against gram-negative bacteria which include Proteus vulgaris, Klebsiella pneumoniae, Shigella dysenteriae, Pseudomonas aeruginosa, and E. coli $[22,23]$. Extract of ethanol from the plant also exhibited an antibacterial effect on both gram-positive (Clostridium sporogenes, Staphylococcus pyogenes and $S$. aureus) as well as the gram-negative (E. coli and Salmonella typhi) bacteria [23-25]. Nevertheless, a contradiction occurred in the findings regarding the activity of the ethanol extract obtained from $V$. amygdalina. (Ogbulie et al., 2007) showed that the best solvent and the technique to give the optimal antibacterial effect of $V$. amygdalina are ethanol and Soxhlet extractions. On the other hand, despite the inhibitory effect of $V$. amygdalina on $S$. aureus, [26] showed that this extract could not inhibit the methicillin-resistant (MRSA UELSHB 102, UELSHB) and methicillin-sensitive (MRSA NCTC 6571) strains of the bacteria while chloroform, water and blended extract of $V$. amygdalina leaves exhibited low inhibitory effect on its growth.

\subsection{KALANCHOE CRENATA}

The external applications of $K$. crenata are the same as those of Bryophyllum pinnatum [27]. The juice obtained by squeezing the leaves that have been passed over fire slightly is most commonly used for the treatment of headache, general debility, dysentery, smallpox and convulsion. One or two drops of the leaf juice are dropped into the ear for earaches. A poultice of the leaves is applied over wounds and sores. The leaves can be boiled in water and the extract is given as a sedative for asthma and palpitation [27]. Similarly, the leave extract mixed with honey and salt serves as a remedy for chronic cough. Also, dried leaves extract is applied to the infected wound [28].

The treatment of rheumatism, as well as stiff joint in East Africa, is done by slightly heating the leaves and rubbing it over the human body [29]. Solvent type as well as the preparation technique utilized strongly affect the antipathogenic (antimicrobial) potency of plants [26, 30,31]. On the basis of this background, in-vitro antimicrobial activities of the extracts $B$. pinnatum and $K$. crenata from various solvents were tested against clinically important pathogens in the work done by [27].

[27] have reported that $K$. crenata extracts have unequal effects on tested organisms which includes Gram-negative E. coli ATCC 25922, E. coli, Pseudomonas aeruginosa, Salmonella paratyphi, Klebsiella pneumoniae, Shigella flexneri, Citrobacter spp, Gram-positive organisms S. aureus ATCC 25213, Bacillus subtilis, S. aureus, Enterococcus faecalis, and a fungus Candida albicans excluding "Omidun" extract of $K$. crenata which revealed no substantial activity. It was further suggested by Aibinu et al., that extracts of $K$. crenata showed broad spectrum in their activities and that extracts from the squeezed leaves of $K$. crenata proved to be the most active; it exhibited improved antimicrobial activity compared to leaves from $B$. pinnatum prepared using the same method. The effect of $K$. Crenata has manifested against the Grampositive as well as the Gram-negative organisms with its activity greatly manifested on the Gram-negative organisms [27]. It was also reported that palm wine extracted from $K$. crenata showed higher activity on 
the E. coli organisms tested, Citrobacter spp and Salmonella paratyphi and further explain that utilization of palm-wine as a solvent release some amount of active elements which shows high activity against enteric organisms. The different antimicrobial potency exhibited by the plant extract dissolved in different solvents as revealed by various researchers, confirms the traditional use of the plant in the treatment of microbial infections such as sore, dysentery, ear infections, abscesses as well as wound infections. In the work reported by [27] stated that aqueous extracts, as well as methanol extraction of dried leaves of $\mathrm{K}$. crenata, exhibited moderate antibacterial activities.

\subsection{MICROBIAL RESISTANCE}

The development and widespread use of antibiotics must rank as the most remarkable of all medical advances made in the 20th century. Overconfident assertions that infectious diseases would soon be a thing of the past, however, the threat of resistant strains casts a shadow over all the past achievements of antibiotics [32]. Recently, there is the upsurge of antibiotic-resistant strains of important clinical pathogens, which led to the development of new bacterial species that are multi-resistant [33-35]. Mortality and morbidity have suddenly increased, owing to the high cost coupled with non-availability of new generation antibiotics [36]. There is, therefore, the need to unravel other sources with proven antimicrobial potency. This paved way for researchers to delve into more effective antimicrobial agents of plant origin, with much emphasis to discover active ingredient with a potential effect on infectious microbes to synthesize new antimicrobial drugs [37, 38]. The major aim of scientists now must be to develop new antibiotics or other therapeutic strategies at a pace greater than that at which bacteria are developing resistance [39]. In 2000, the Food and Drugs Administration approved a new synthetic agent shown to be effective against both MRSA and vancomycin-resistant Enterococcus faecalis. Linezolid (Zyvox), which works by blocking the initiation of protein synthesis, belongs to a new class of antibiotics called oxazolidinones [39]. It is the first new anti-MRSA compound to be introduced for more than 40 years. Another approach to countering resistant forms is to identify and target the mechanism by which the bacteria combat antibiotic therapy [39]. A team at Rockefeller University in New York have identified two genes that enable resistant forms to rebuild their cell walls after antibiotic treatment. Therefore targeting these genes, they hope to restore the potency of a cell wall inhibitor such as penicillin [39].

[40] has reported S. typhi resistance to many antibiotics on the market. Antimicrobial susceptibility testing was performed on all serovar typhi isolates by using the Kirby-Bauer disk diffusion method for ampicillin, chloramphenicol, tetracycline, trimethoprim, gentamicin, amoxicillin, ciprofloxacin and ceftriaxone. It was found that S.typhi was resistant to chloramphenicol (73\%), trimethoprim (71\%), ampicillin /amoxicillin (70\%) tetracycline (64\%), gentamicin (46\%) and amoxicillin/clavulanic acid (24\%) but susceptible to ciprofloxacin and ceftriaxone.

[41] also collected S. typhi samples from the University College Hospital, Ibadan, Nigeria and exposed to ten standard different antibiotics and also to crude extract of Phyllanthus amarus and Paraquetina nigrescent. Ethanolic extracts of $P$. amarus had the strongest activity against $S$. typhi with $8.0 \mathrm{~mm}$ zone of growth inhibition followed by hot water $(4.7 \mathrm{~mm})$ and cold water $(3.8 \mathrm{~mm})$ with statistically significant 
at $\mathrm{P}=0.05$ when compared with hot and cold water extracts. Amongst the commercial antibiotics examined, it was concluded that ciprofloxacin had the highest zone of growth inhibition of $9.0 \mathrm{~mm}$; Ofloxacin $(6.0 \mathrm{~mm})$ Amoxicillin, $(4.0 \mathrm{~mm})$ while other antibiotics had no effect on test organism. Unfortunately, the resistance of $S$. typhi strains to all of these antibiotics is becoming more common globally. As such, appropriate treatment varies with the geographic distribution of resistant strains [41].

[42] evaluated the current fluoroquinolones susceptibility criteria and a nalidixic acid screening test in Salmonella enterica serovar Typhi and Paratyphi A. All the isolates were found susceptible to ciprofloxacin and ofloxacin. However, some research has proven that the combined effects of two drugs have shown more antimicrobial potency than the effects of the two when applied separately. That is, an antibiotic which not having much effect when combined with another will produce an effect greater than the separate effects of each drug.

\subsection{COMBINATION CHEMOTHERAPY}

The development of resistance to first-line antimicrobial therapies has led to recommendations for combination therapies for the treatment of some infections [43]. The accomplishment of combination therapies in recent times has been revealed by researchers, owing to their application in the treatment of ailment. However, few reports have been given on the in vitro actions that result from various combination of these drugs. For example, an assessment of the in vitro action of azithromycin combined with gentamicin showed growth inhibition which warranted a clinical trial of this combination in treating gonorrhoea infections [43].

Base on this idea some bacteria that used to be monoresistant to certain antibiotics are now being susceptible to this same antibiotic combined with another [43].

In this experiment, the separate effect produced by $V$. amygdalina and $K$. crenata is being experimented and then compared to the combined effect produced by the two extracts with an initial hypothesis made that bacteria strain would be sensitive to the various extracts.

\section{Material \& Method}

\subsection{PLANT MATERIALS}

The leaves of $V$. amygdalina were collected from the University of Cape Coast (UCC) Science Botanical Garden at Amamoma and were authenticated at the Cape Coast University's herbarium by Mr. Otoo.

\subsection{PREPARATION OF EXTRACTS}

The method (Mother Tincture) devised by Jean-Michael (1994) was employed for the extraction. The leaves of the plant were air-dried for 2 days and then finally dried in an oven at $45^{\circ} \mathrm{C}$ for 3 days as described by [44]. The dried leaves were then blended using an electric blender and the powder stored in a sterile bottle at room temperature [45]. Fifty grams (50) g of the powdered plant leaves were weighed and 
dissolved in $450 \mathrm{~mL}$ 70\% ethanol. The mixture was then held in an airtight container, kept in a cool dark place for 3 days and then filtered using a sterile filter paper. The filtrate retrieved was concentrated by evaporation using a water bath at $97^{\circ} \mathrm{C}$ and then stored in sterile bottles until it is needed.

\subsection{BACTERIA SPECIES}

Strains of Salmonella species were acquired from the Microbiology Laboratory of Centre for Plant Medicine Research, Mampong in the Eastern Region of Ghana.

Consent was sought from the laboraory technician, that the strains were not going to be used on animals or humans for the experimental research but was going to be an in-vitro experiment, therefore no ethical clearance was needed.

\subsection{PREPARATION OF EXTRACT CONCENTRATIONS}

Thousand milligrams (1000 mg) each of the $V$. amygdalina and $K$. crenata extracts were weighed using weighing balance and together dissolved into $20 \mathrm{~mL}$ of $2 \%$ DMSO in a clean and well-dried container. Another $2000 \mathrm{mg}$ each of the extracts was weighed and dissolved in $20 \mathrm{~mL}$ each of $2 \%$ DMSO in separate containers. For each of the stocks prepared $(100 \mathrm{mg} / \mathrm{ml})$, half of the volume $(10 \mathrm{~mL})$ was taken and serially diluted to get concentrations of $50 \mathrm{mg} / \mathrm{mL}, 25 \mathrm{mg} / \mathrm{mL}$, and $12.25 \mathrm{mg} / \mathrm{mL}$ into separate containers. The containers with their contents were covered and stored in the refrigerator until they were needed for use [46].

\subsection{PHYTOCHEMICAL SCREENING}

The phytochemical constituents of both $V$. amygdalina and $K$. crenata ethanolic extracts were determined using methods described by [47].

\subsection{PREPARATION OF INOCULUM}

The pure culture of the organisms from the cotton swab was plated out on Salmonella-Shigella agar and incubated at $37^{\circ} \mathrm{C}$ for 24 hours. After incubation, the colony of the organisms was taken and inoculated into $7 \mathrm{~mL}$ of peptone water in test tubes and shook vigorously so as to obtain homogeneity of the solution as described by [17].

\subsection{MICROBIAL SENSITIVITY TEST}

Agar well diffusion method as described by [44] was employed using Salmonella-Shigella agar. Agar plates were prepared according to the manufacturer's specification aseptically to a thickness of 5-6 mm. The agar was then left to solidify and the plates then upturned to prevent condensate from coming into contact with the agar surface. To ensure sterility, the plates were incubated at $37^{\circ} \mathrm{C}$ for 24 hours. The prepared inoculum of the bacteria species was inoculated onto the prepared media by dipping cotton swab into the inoculum and wiping it on the surface of the media. The inoculated agar plates with the lids covered were allowed to dry at room temperature. Thereafter, sterile pipette tips (5.0 mm diameter) were used to punch wells in the seeded Salmonella-Shigella agar. The agar plugs were removed with a 
flamed and cooled inoculating loop. Into the separate well was poured different concentrations of the various plant's extracts and the solvent blank (2\% DMSO). Standard antibiotic (Ciprofloxacin) which salmonella is known to be sensitive to was used as a positive control [42]. The experiment for each extract and organism was repeated in triplicates so in all 12 plates were prepared. The samples were incubated at $37^{\circ} \mathrm{C}$ for 24 hours. The diameter of zones of inhibition on the plates was measured using a transparent meter rule and recorded. The measured zones of inhibition of the different extracts were compared. The zones of inhibition created by the various quantities (concentrations) of the extracts also were compared [17].

\section{Results}

\section{Results showing the phytochemical screening of Vernonia amygdalina}

Table 1 shows the phytochemical constituent of the leaves of Vernonia amygdalina. The results obtained from the phytochemicals analysis showed the presence of some secondary metabolite like tannins, saponins, terpenoids, flavonoids, glycosides, alkaloids, anthraquinones. All tested positive except Anthraquinones which tested negative.

\begin{tabular}{lc}
\hline TEST & RESULTS \\
\hline Reducing sugar & + \\
Saponins & + \\
\hline Flavonoids & + \\
\hline Anthraquinones & - \\
\hline Terpenoids & + \\
\hline Glycosides & + \\
Alkaloids & + \\
\hline Tannins & + \\
\hline
\end{tabular}

+ indicates positive results.

- indicates negative result.

2. Results showing the phytochemical screening of Kalanchoe crenata 


\begin{tabular}{lc}
\hline TEST & RESULTS \\
\hline Alkaloids & + \\
Glycosides & + \\
\hline Phenolics & + \\
Flavonoids & - \\
Triterpenes & + \\
\hline Anthraquinones & + \\
Steroids & + \\
Saponins & + \\
Tannins & + \\
Terpenoids & + \\
\hline
\end{tabular}

+ indicates positive results.

- indicates negative result.

Antimicrobial actions of the extracts acquired from $V$. amygdalina as well as $K$. crenata leaves and a mixture of the two plant extracts, using $70 \%$ ethanol on the test organisms are listed in Table 3 . The screening of antimicrobial activity of extracts was assayed in vitro by the agar diffusion method and using Ciprofloxacin as a positive control drug in all samples.

The antimicrobial effect was determined by taking the diameter of zone of inhibition recorded. The average and standard error mean (SEM) of the zone of inhibition for each concentration from each of the triplicates were calculated and recorded in Table 3. 
Table 3

Zone of inhibition of extracts and the combined effect on Salmonella typhi

\begin{tabular}{|c|c|c|c|c|}
\hline \multirow{2}{*}{$\begin{array}{l}\text { Concentration of extracts } \\
(\mathrm{mg} / \mathrm{ml})\end{array}$} & \multicolumn{3}{|c|}{ Zone of Inhibition (mm) } & \multirow{2}{*}{$\begin{array}{l}\text { Control } \\
\text { Ciprofloxacin } \\
(5 \mu \mathrm{g} / \mathrm{ml})\end{array}$} \\
\hline & $\begin{array}{l}\text { V. } \\
\text { amygdalina }\end{array}$ & $\begin{array}{l}\text { K. } \\
\text { crenata }\end{array}$ & $\begin{array}{l}\text { Combined } \\
\text { effect }\end{array}$ & \\
\hline 100.00 & $5 \pm 5.000$ & $\begin{array}{l}20 \pm \\
0.882\end{array}$ & $14 \pm 4.667$ & $26 \pm 1.333$ \\
\hline 50.00 & $5 \pm 5.000$ & $\begin{array}{l}12 \pm \\
6.245\end{array}$ & $0 \pm 0.000$ & \\
\hline 25.00 & $6 \pm 5.667$ & $\begin{array}{l}11 \pm \\
7.311\end{array}$ & $0 \pm 0.000$ & \\
\hline 12.25 & $5 \pm 5.000$ & $7 \pm 7.333$ & $0 \pm 0.000$ & \\
\hline
\end{tabular}

The values are mean from ZOI of three replicates \pm standard error mean

The $K$. crenata extracts was found to be most potent antimicrobial agent with its highest ZOI of $20 \mathrm{~mm}$ at $100 \mathrm{mg} / \mathrm{ml}$ and lowest ZOI of $7 \mathrm{~mm}$ at $12.25 \mathrm{mg} / \mathrm{ml}$; comparing with the $V$. amygdalina extract and the combined extracts it is found the $K$. crenata is still the extract that produced the highest $Z O I$ at their lowest concentrations.

\section{Discussion}

The antimicrobial action was determined by taking the diameter of the zone of inhibition and recorded. The $K$. crenata extracts was found to be most potent antimicrobial agent with its highest zone of inhibition of $20 \mathrm{~mm}$ at $100 \mathrm{mg} / \mathrm{ml}$ and lowest zone of inhibition of $7 \mathrm{~mm}$ at $12.25 \mathrm{mg} / \mathrm{ml}$ (Fig. 1.0); comparing with the $V$. amygdalina extract and the combined extracts it is found the $K$. crenata is still the extract that produced the highest zone of inhibition even at their lowest concentrations (Table 1). The $V$. amygdalina, on the other hand, produced a consistent zone of inhibition with values of 5 and $6 \mathrm{~mm}$. The combined effect of the two extracts did not produce any antimicrobial effect at all the concentrations prepared except for the $100 \mathrm{mg} / \mathrm{ml}$ which revealed an inhibition zone of $14 \mathrm{~mm}$ in diameter. The results for $V$. amygdalina are in accordance with some previous studies done on this aspect. [48], reported a zone of inhibition ranging from 4-8 $\mathrm{mm}$ for Salmonella species; the results of $V$. amygdalina from this research $5 \mathrm{~mm}$ and $6 \mathrm{~mm}$ falls within this range reported by [48]. The susceptibility of the organisms to $V$. amygdalina extracts elucidates their use for therapeutic purposes in Nigeria for the cure of infections such as dysentery.

The microbes showed a slight high degree of resistance against the $V$. amygdalina more than against the $K$. crenata; From Table 1 it can be seen that at different concentrations $V$. amygdalina had a lower zone of inhibition than $K$. crenata. 
The combined effect produced a zone inhibition diameter only at the $100 \mathrm{mg} / \mathrm{ml}$ with a zone of inhibition value of $14 \mathrm{~mm}$. The subsequent lower concentrations did not show any activity against the microbes even though their corresponding concentrations for $K$. crenata showed activity with decreasing effect directly proportional to the decrease in concentration. This shows that $V$. amygdalina and $K$. cranata together may produce an antagonistic effect. At lower concentrations $(<100 \mathrm{mg} / \mathrm{ml}$ based on this research) there was no activity. However, at higher concentrations ( $\geq 100 \mathrm{mg} / \mathrm{ml}$ ) there was an activity with a $14 \mathrm{~mm}$ inhibition zone. This result may be due to the fact that the two plants extract when combined produce an antagonistic effect (especially at lower doses of each extract in the mixture). Therefore the activity showed at the $100 \mathrm{mg} / \mathrm{ml}$ concentration may be due to the fact that one of the plants is more potent than the other so as there is increase in concentrations of the combined and as such, the relative increase in the individual concentrations the more potent moiety (in this case $K$. crenata) of the mixture produced its effect but with a lesser activity; in this research $K$. crenata is the one that contributed more of the effect in the combined extract (zone of inhibition: $14 \mathrm{~mm}$ ) since at all concentrations it had higher activity than $V$. amygdalina in their separate forms; therefore when comparing the zone of inhibition of $K$. crenata and " $K$. crenata in mixture" (combined extract) it is seen that at $100 \mathrm{mg} / \mathrm{ml}$ the zone of inhibition produced by $K$. crenata was reduced from $20 \mathrm{~mm}$ to $14 \mathrm{~mm}$ (Table 1) in the effect produced by " $K$. crenata in mixture" (combined extract). Note that $K$. crenata at the same $100 \mathrm{mg} / \mathrm{ml}$ concentration produced more activity singly than when it was combined with $V$. amygdalina.

The standard antibiotic ( $5 \mu \mathrm{g}$ Ciprofloxacin) produced a zone of inhibition of $26 \mathrm{~mm}$. This result is in line with the standard zone of inhibition range provided by the Clinical Laboratory Standard Institute (CLSI). According to $\mathrm{CLSI}$ reference ( $\mathrm{ZOI} \leq 15 \mathrm{~mm}$ is resistance, $\mathrm{ZOI} \geq 21 \mathrm{~mm}$ implies sensitivity to Cipro). [40] also reported a zone of inhibition of $25.8125 \pm 1.875 \mathrm{~mm}$ for Salmonella typhi sensitive to Ciprofloxacin. However [41], reported that ciprofloxacin had a zone of growth inhibition of $9.0 \mathrm{~mm}$ for S. typhi, this which implies resistance but the finding was reported as sensitivity.

The phytochemical screening of $K$. crenata extract revealed the presence of anthraquinones which was absent in V. amygdalina.

Statistical analysis from the two-way ANOVA at P-value of 0.05 exhibited a significant difference between the effects produced by the different extracts, though there were no significant differences in the effects produced by the concentrations. For the concentrations, the calculated F-ratio, $F(3,6)=3.194$ and P-value $=0.1052$. The P-value was observed to be greater than 0.05 after calculation, which implies there is no significant difference among the effects produced by the different concentrations.

For the extracts the calculated F-ratio, F $(2,6)=5.995$ and P-value $=0.0371$. The P-value obtained after calculation was less than 0.05 which implies there exist significant difference among the effects produced by the different extracts.

\section{Conclusion}


The combined effect was not sensitive to the Salmonella strain. However, K. cranata was sensitive and it is the extract that produced the maximum effects at all the concentrations prepared whereas $V$. amygdalina was also sensitive but with an almost constant zone of inhibition at all concentrations. It can also be concluded that the salmonella strain was resistant to $V$. amygdalina than to K. crenata. At Pvalue $=0.05$ there was a substantial difference in the sensitivity of the bacteria to the different extracts.

\section{Recommendation}

$K$. crenata has shown potency for antimicrobial activity than $V$. amygdalina however further works must be done on the $V$. amygdalina and $K$. crenata to test for the actual phytochemicals that are producing the antimicrobial effects. The test should be repeated using gram-positive microbes especially to compare the combined effect to that of this research and also using higher concentrations of the combined effect.

\section{Declarations}

\section{- ACKNOWLEDGEMENTS}

N/A

\section{- FUNDING}

No funding was received for preparation of this letter.

\section{- AVAILABILITY OF SUPPORTING DATA}

All data used for the study have been included in this article.

\section{- AUTHOR(S) INFORMATION}

\section{Affiliations}

${ }^{1}$ Emmanuel Effah-Yeboah, ${ }^{1}$ Emmanuel Agyapong Asare, ${ }^{1,3}$ Gadafı Iddrisu Balali

1. University of Education, Winneba - Ghana

2. Kwame Nkrumah University of Science and Technology, Kumasi - Ghana

\section{Corresponding author}

Emmanuel Effah-Yeboah, University of Education, Winneba eeyeboah@uew.edu.gh

$+233242953495$

\section{- ETHICS DECLARATIONS}




\section{Ethics approval and consent to participate}

$N / A$

\section{Consent for publication}

All authors have consented to the publication.

\section{Competing interests}

The authors declare that there is no conflict of interest.

\section{References}

1. Mahon, C.R., D.C. Lehman, and G. Manuselis, Textbook of diagnostic microbiology-e-book. 2018 : Elsevier Health Sciences.

2. Batoni, G., G. Maisetta, and S. Esin, Antimicrobial peptides and their interaction with biofilms of medically relevant bacteria. Biochimica et Biophysica Acta (BBA)-Biomembranes, 2016. 1858(5): p. 1044-1060.

3. Turker, G., et al., Changes in microbial community structures due to varying operational conditions in the anaerobic digestion of oxytetracycline-medicated cow manure. Applied microbiology and biotechnology, 2016. 100(14): p. 6469-6479.

4. Finlay, B.B. and J.M. Finlay, The Whole-Body Microbiome: How to Harness Microbes-Inside and Out -for Lifelong Health. 2019: The Experiment.

5. Nash, A.A., R.G. Dalziel, and J.R. Fitzgerald, Mims' pathogenesis of infectious disease. 2015: Academic Press.

6. De Jong, B., Y. Andersson, and K. Ekdahl, Effect of regulation and education on reptile-associated salmonellosis. Emerging infectious diseases, 2005. 11(3): p. 398.

7. Organization, W.H., Antimicrobial resistance and primary health care: brief. 2018, World Health Organization.

8. Brown, J., S. Cairncross, and J.H. Ensink, Water, sanitation, hygiene and enteric infections in children. Archives of disease in childhood, 2013. 98(8): p. 629-634.

9. Zaki, S.A. and S. Karande, Multidrug-resistant typhoid fever: a review. The Journal of Infection in Developing Countries, 2011. 5(05): p. 324-337.

10. Akram, J., et al., Extensively Drug-Resistant (XDR) Typhoid: Evolution, Prevention, and Its Management. BioMed Research International, 2020. 2020.

11. Acheampong, G., et al., Chromosomal and plasmid-mediated fluoroquinolone resistance in human Salmonella enterica infection in Ghana. BMC infectious diseases, 2019. 19(1): p. 1-10.

12. Maghrani, M., et al., Acute diuretic effect of aqueous extract of Retama raetam in normal rats. Journal of Ethnopharmacology, 2005. 99(1): p. 31-35. 
13. Mbatchou, V.C., K.O. Nabayire, and Y. Akuoko, Vernonia amygdalina Leaf: Unveiling its antacid and carminative properties In Vitro. Current Science, 2017. 3(3): p. 148-155.

14. Ademosun, A.O., et al., Modulation of cholinergic, monoaminergic, and purinergic enzymes of the brain functions by bitter (Vernonia amygdalina) and water bitter (Struchium sparganophora) leaves extracts: comparison of phenolic constituents versus nootropic potentials. Comparative Clinical Pathology, 2017. 26(6): p. 1267-1272.

15. Oshim, I.O., et al., Kinetics of minimum inhibitory concentration, minimum bactericidal concentration and minimum fungicidal concentration of Vernonia amygdalina (Bitter leaf) on microorganisms isolated from wound infections. International Journal of Surgical Research, 2016. 5(1): p. 8-14.

16. Agbankpé, A., et al., In vitro antibacterial effects of Crateva adansonii, Vernonia amygdalina and Sesamum radiatum used for the treatment of infectious diarrhoeas in Benin. Journal of Infectious Diseases \& Therapy, 2016. 2016.

17. Olamide, S.O. and G. Agu, The Assessment of the antimicrobial activities of Ocimum gratissimum (wild basil) and Vernonia amygdalina (Bitter leaf) on some enteric pathogen causing dysentery or diarrhea in patients. Int J Eng Sci, 2013. 2(9): p. 83-96.

18. Adetunji, C., O. Olaniyi, and A. Ogunkunle, Bacterial activity of crude extracts of Vernonia amygdalina on clinical isolates. Journal of Microbiology and Antimicrobials, 2013. 5(6): p. 60-64.

19. Usunomena, U. and O.P. Ngozi, Phytochemical analysis and proximate composition of Vernonia amygdalina. 2016.

20. Usunobun, U. and N. Okolie, Phytochemical, trace and mineral composition of Vernonia amygdalina leaves. International Journal of Biological and Pharmaceutical Research, 2015. 6(5): p. 393-399.

21. Bukar, A.M., et al., Antibacterial activityof aqueous and ethanolic leaf extracts of vernonia amygdalina on selected species of gram positive and gram negative bacteria. International Journal of Environment, 2013. 2(1): p. 147-152.

22. Chukwuemeka, N.O., et al., Antibacterial assay and reversion of carbon tetrachloride induced liver damage on wistar mice by Vernonia amygdalina. Delile. Pakistan journal of pharmaceutical sciences, 2018. 31(4).

23. Yeap, S.K., et al., Vernonia amygdalina, an ethnoveterinary and ethnomedical used green vegetable with multiple bio-activities. Journal of medicinal plants research, 2010. 4(25): p. 2787-2812.

24. Asuzu, C.U., Bitter herbs of eastern Nigeria (Gongronema latifolium, Vernonia amygdalina and Vitex doniana): A review. African Journal of Traditional, Complementary and Alternative Medicines, 2018. 15(3): p. 47-56.

25. Ogbulie, T., J. Ogbulie, and H. Njoku, Comparative study on the microbiology and shelf life stability of palm wine from Elaeis guineensis and Raphia hookeri obtained from Okigwe, Nigeria. African Journal of Biotechnology, 2007. 6(7).

26. Pesewu, G.A., R.R. Cutler, and D.P. Humber, Antibacterial activity of plants used in traditional medicines of Ghana with particular reference to MRSA. Journal of ethnopharmacology, 2008. 116(1): p. 102-111. 
27. Odugbemi, T.O., et al., Medicinal plants useful for malaria therapy in Okeigbo, Ondo State, Southwest Nigeria. African Journal of Traditional, Complementary and Alternative Medicines, 2007. 4(2): p. 191198.

28. Adetutu, A., W.A. Morgan, and O. Corcoran, Ethnopharmacological survey and in vitro evaluation of wound-healing plants used in South-western Nigeria. Journal of Ethnopharmacology, 2011. 137(1): p. 50-56.

29. Iwu, M.M., Pharmacognostical profile of selected medicinal plants. 2014.

30. Uzoigwe, C. and O. Agwa, Antimicrobial activity of Vernonia amygdalina on selected urinary tract pathogens. African Journal of Microbiology Research, 2011. 5(12): p. 1467-1472.

31. Alo, M., et al., Antibacterial activity of water, ethanol and methanol extracts of Ocimum gratissimum, Vernonia amygdalina and Aframomum melegueta. Adv. Appl. Sci. Res, 2012. 3(2): p. 844-848.

32. Todd, K., The promising viral threat to bacterial resistance: The uncertain patentability of phage therapeutics and the necessity of alternative incentives. Duke LJ, 2018. 68: p. 767.

33. Wellington, E.M., et al., The role of the natural environment in the emergence of antibiotic resistance in Gram-negative bacteria. The Lancet infectious diseases, 2013. 13(2): p. 155-165.

34. Warnke, P.H., et al., The battle against multi-resistant strains: renaissance of antimicrobial essential oils as a promising force to fight hospital-acquired infections. Journal of Cranio-Maxillofacial Surgery, 2009. 37(7): p. 392-397.

35. WHO, Antimicrobial resistance and primary health care: brief. 2018, World Health Organization.

36. Mondal, C., A Study to Evaluate Anti-microbial properties of an Indian medicinal plant-with particular reference to multidrug-resistant phenotypes. 2012.

37. Pretorius, J., et al., Purification and identification of antibacterial compounds from Euclea crispa subsp. crispa (Ebenaceae) leaves. South African journal of botany, 2003. 69(4): p. 579-586.

38. Suarez, M., et al., Structure-function characterization and optimization of a plant-derived antibacterial peptide. Antimicrobial Agents and Chemotherapy, 2005. 49(9): p. 3847-3857.

39. Hogg, S., Essential microbiology. 2013: John Wiley \& Sons.

40. Agyekum, A., Prevalence of Bacteria Causing Bacteraemia in Children Under Five Years in Agogo, Asante-Akyem and Their Antimicrobial Susceptibility Patterns. 2010.

41. Oluwafemi, F. and F. Debiri, Antimicrobial effect of Phyllanthus amarus and Parquetina nigrescens on Salmonella typhi. African Journal of Biomedical Research, 2008. 11(2).

42. Acharya, D., et al., Current fluoroquinolone susceptibility criteria for Salmonella needs re-evaluation. Kathmandu University Medical Journal, 2012. 10(1): p. 66-71.

43. Pettus, K., S. Sharpe, and J.R. Papp, In vitro assessment of dual drug combinations to inhibit growth of Neisseria gonorrhoeae. Antimicrobial agents and chemotherapy, 2015. 59(4): p. 2443-2445.

44. Agu, G., et al., Prevalence of diarrhoea agents and the in-vitro effects of three plant extracts on the growth of the isolates. 2013. 
45. Akinsulire, O.R., et al., In vitro antimicrobial activity of crude extracts from plants Bryophyllum pinnatum and Kalanchoe crenata. African Journal of Traditional, Complementary and Alternative Medicines, 2007. 4(3): p. 338-344.

46. Anibijuwon, l., et al., Antimicrobial activities of Vernonia amygdalina against oral microbes. 2012.

47. Ayoola, G., et al., Phytochemical screening and antioxidant activities of some selected medicinal plants used for malaria therapy in Southwestern Nigeria. Tropical Journal of Pharmaceutical Research, 2008. 7(3): p. 1019-1024.

48. Isa, M., et al., Prevalence of salmonella agglutinins among patients attending hospitals in biu, Borno State, Nigeria. Archives of Applied Science Research, 2013. 5(1): p. 83-87.

\section{Figures}

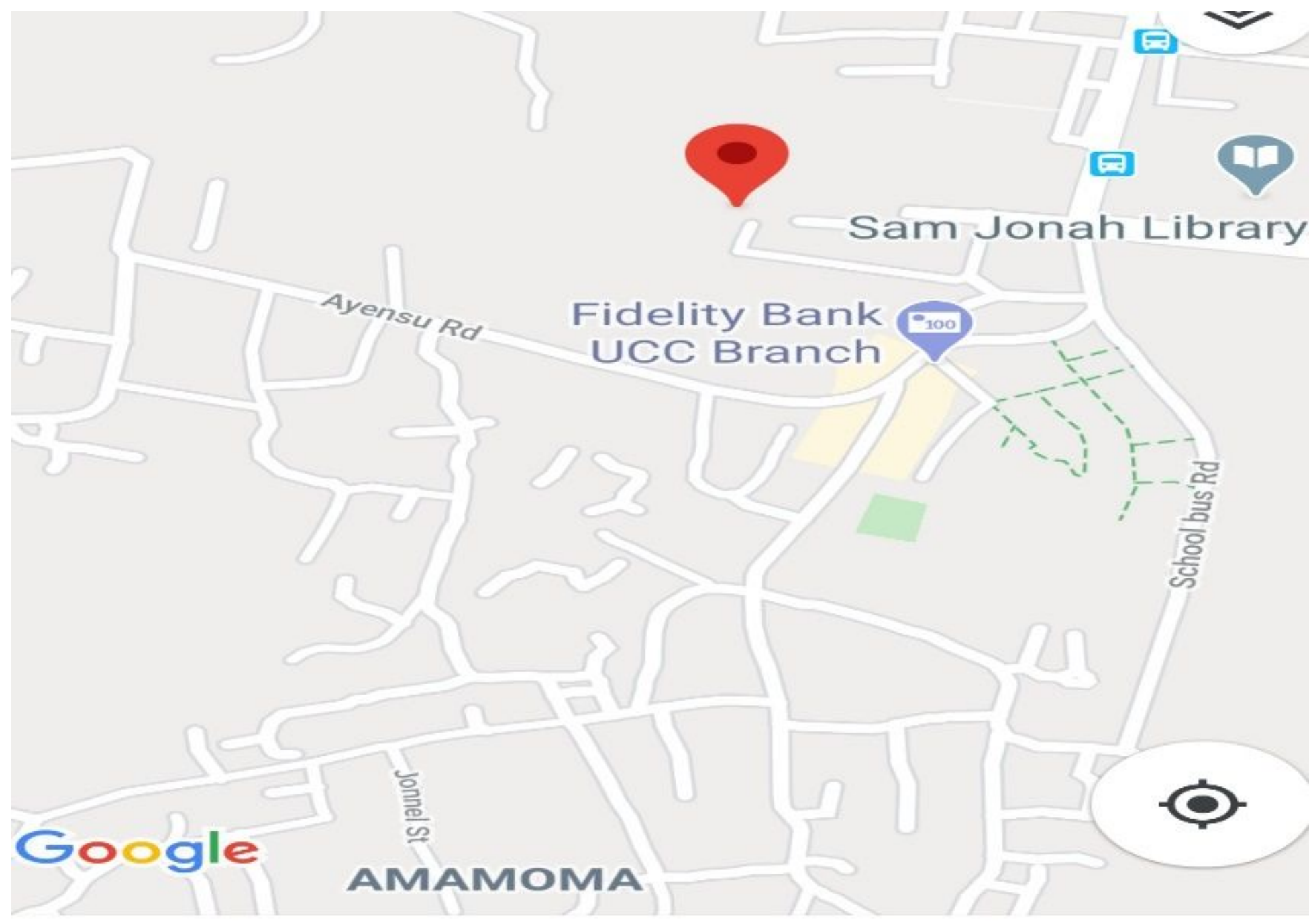

\section{Figure 1}

Figure 1 